\title{
Association between sensorimotor impairments and functional brain changes in patients with low back pain: a critical review
}

Nina Goossens MSc, ${ }^{1}$ Sofie Rummens MD, ${ }^{2}$ Lotte Janssens PhD,,${ }^{1,3}$ Karen Caeyenberghs PhD, ${ }^{4}$ Simon Brumagne $\mathrm{PhD}^{1}$

${ }^{1}$ KU Leuven - University of Leuven, Department of Rehabilitation Sciences, Tervuursevest 101, box 1501, B-3001 Leuven, Belgium

${ }^{2}$ University Hospitals Leuven, Department of Physical Medicine and Rehabilitation, Herestraat 49, B-3000 Leuven, Belgium

${ }^{3}$ Hasselt University, BIOMED, REVAL, Agoralaan, B-3590 Diepenbeek, Belgium

${ }^{4}$ School of Psychology, Faculty of Health Sciences, Australian Catholic University, Melbourne Campus (St Patrick), Locked Bag 4115, Fitzroy MDC, VIC 3065, Australia

\section{Correspondence:}

Nina Goossens

Mailing address: KU Leuven - University of Leuven, Department of Rehabilitation Sciences Musculoskeletal Rehabilitation Research Group, Tervuursevest 101, box 1501, B-3001 Leuven, Belgium

Phone number: +32 163790 40, Fax number: +32 16329197

Email address: Nina.Goossens@kuleuven.be 


\section{Author Disclosures:}

Competing Interests: All authors (NG, SR, LJ, KC, SB) declare no conflicts of interest.

Funding or grants or equipment provided for the project from any source: This study was funded by the Agency for Innovation by Science and Technology (Agentschap voor Innovatie door Wetenschap en Technologie IWT) (PhD Grant for Strategic Basic Research Nina Goossens, grant number ZKC9172-00-W01) and by the Research Foundation Flanders (Fonds Wetenschappelijk Onderzoek FWO) (Postdoctoral Fellowship Lotte Janssens, grant number $12 \mathrm{M} 9815 \mathrm{~N})$.

Financial benefits to the authors: All authors declare to have no financial benefit from this manuscript.

Details on any previous presentation of the research, manuscript, or abstract in any form: This manuscript or abstract has not been presented anywhere in any form. 


\begin{abstract}
Low back pain (LBP) coincides with sensorimotor impairments, e.g., reduced lumbosacral tactile and proprioceptive acuity and postural control deficits. Recent functional magnetic resonance imaging (fMRI) studies suggest that sensorimotor impairments in LBP may be associated with brain changes. However, no consensus exists regarding the relationship between functional brain changes and sensorimotor behavior in LBP. Therefore, this review critically discusses the available fMRI studies on brain activation related to non-nociceptive somatosensory stimulation and motor performance in individuals with LBP. Four electronic databases were searched, yielding nine relevant studies. Patients with LBP showed reduced sensorimotor-related brain activation and a reorganized lumbar spine representation in higher-order (multi)sensory processing and motor regions, including primary and secondary somatosensory cortices, supplementary motor area and superior temporal gyrus. These results may support behavioral findings of sensorimotor impairments in LBP. Additionally, patients with LBP displayed widespread increased sensorimotor-evoked brain activation in regions often associated with abnormal pain processing. Over-activation in these regions could indicate an overresponsiveness to sensory inputs that signal potential harm to the spine, thereby inducing overgeneralized protective responses. Hence, functional brain changes could contribute to the development and recurrence of LBP. However, future studies investigating the causality between sensorimotor-related brain function and LBP are imperative.
\end{abstract}

\title{
Keywords
}

Low back pain; Functional MRI; Proprioception; Movement 


\section{Introduction}

Low back pain (LBP) is a highly prevalent health condition ${ }^{1,2}$ characterized by recurring episodes and a high risk of chronification..$^{3-7}$ Currently, LBP has been identified as the main cause of disability worldwide. ${ }^{8,9}$ The majority of LBP complaints are "non-specific", meaning that the pain cannot be ascribed to a recognizable specific pathology such as an inflammatory disorder or vertebral fracture. ${ }^{10}$ This highlights the need to elucidate the mechanisms that underlie the development and recurrence of LBP. ${ }^{11}$

Sensorimotor impairments have been identified as possible key factors in the development and recurrence of non-specific LBP. ${ }^{12,13}$ For example, patients with LBP show a disrupted body schema of the trunk ${ }^{14,15}$ and a decreased tactile and proprioceptive acuity at the lumbar spine compared to healthy controls. ${ }^{16-20}$ To compensate for the less accurate lumbosacral proprioceptive signals, patients with LBP predominantly use ankle muscle proprioception during postural control. ${ }^{21-23}$ This altered use of proprioception in patients with LBP resulted in increased postural sways during challenging postural conditions ${ }^{23,24}$ and was related to a worse sit-to-standto-sit performance compared to healthy subjects. ${ }^{25}$ Altogether, this vast body of behavioral work indicates that patients with LBP show sensorimotor impairments, which can be present prior to the emergence of pain. ${ }^{12,13}$ Unfortunately, the mechanisms underlying these sensorimotor impairments are very poorly understood. Since optimal sensorimotor behavior depends on the adequate central processing and integration of sensory signals, ${ }^{26-28}$ investigating the relation between brain function and sensorimotor behavior in patients with LBP could elucidate the neural mechanisms of sensorimotor impairments in LBP. 
The recently increased use of magnetic resonance imaging (MRI) in LBP research revealed that patients with LBP display structural and functional brain changes (for reviews, see ${ }^{29,30}$ ). For example, resting-state functional MRI (fMRI) studies have convergently shown an increased functional connectivity (FC) in the primary somatosensory cortex (S1), primary motor cortex (M1), insula, medial prefrontal cortex, cingulate cortex and amygdala, and abnormal FC within the default mode network in patients with LBP at rest (for reviews, see ${ }^{29,30}$ ). Additionally, taskrelated fMRI studies reported altered brain activation patterns during the processing of specific stimuli in patients with LBP. The majority of these studies focused on the processing of nociceptive stimuli. They showed that patients with LBP display increased brain activation during nociceptive processing in e.g., S1, S2, insula, prefrontal cortices, anterior cingulate cortex (ACC) and posterior cingulate cortex (PCC) compared to healthy controls. ${ }^{31-34}$

However, very few task-related fMRI studies investigated brain activation related to sensorimotor behavior, i.e. the processing of non-nociceptive somatosensory stimuli and motor performance in individuals with LBP. Consequently, no consensus exists on whether subjects with LBP display functional brain changes related to sensorimotor behavior. However, such knowledge could guide clinicians towards optimizing the evidence-based diagnosis and treatment of LBP. Therefore, this review systematically summarizes and critically discusses the existing fMRI-based findings on brain function during somatosensory processing and motor performance in individuals with LBP. Moreover, methodological considerations for future studies and implications for clinical practice will be discussed. 


\section{Brain activation during somatosensory processing and motor performance in individuals}

with low back pain: search strategy and selection of articles

This critical review using a systematic approach was conducted following the Preferred Reporting Items for Systematic Reviews and Meta-Analyses (PRISMA) guidelines ${ }^{35}$ and reports the required information accordingly (see PRISMA checklist, Supplemental Digital Content 1 , http://links.lww.com/PHM/A520). The protocol was registered in the PROSPERO database with registration number CRD42016053053. Electronic databases Pubmed, CINAHL, Web of Science, and Embase were searched systematically from inception onwards, with the latest search performed on May $26^{\text {th }}, 2017$. The following research question was formulated: "Do individuals with LBP exhibit functional brain changes related to somatosensory processing and/or motor performance, as examined with fMRI techniques?" To promote comparability of results across studies, only studies using resting-state and task-related fMRI (vs. e.g., electroencephalography) were included. The search strategy was formulated, with the assistance of a librarian, by using the PICOS framework. MeSH terms in Pubmed, Emtree terms in Embase and free text words for LBP, fMRI, brain, sensory stimuli (e.g. touch, proprioception) and motor tasks were combined (see Supplemental Digital Content 2, http://links.lww.com/PHM/A521, for a detailed search strategy). No limitations for article type or time of publication were applied.

The obtained articles were entered in EndNote. After de-duplication, two reviewers (NG and SR) independently screened the titles and abstracts of all retrieved articles for eligibility. Then, fulltexts of all relevant articles were screened. In case of disagreement, a third researcher (LJ) screened the article and consensus was reached. To be eligible, studies had to (1) include patients with LBP or healthy individuals with experimentally induced LBP, (2) assess brain function with 
task-related or resting-state fMRI and (3) assess brain activation during or correlate functional brain outcomes with a non-nociceptive somatosensory stimulus or motor task. Studies using stimuli or motor tasks to explicitly induce (more) pain, to investigate the direct effect of pain on brain function, were excluded. Although noxious stimuli and the performance of painaggravating movements may activate sensorimotor brain areas in addition to pain-related areas, studies using such stimuli or movements were excluded to distinguish articles on pain-evoked brain activation from studies on sensorimotor-evoked brain activation. Moreover, studies in healthy subjects with experimentally induced LBP were included only if (1) LBP was induced prior to fMRI scanning to create a "baseline" condition of LBP, and (2) brain activation was then studied during a somatosensory stimulus or motor task that did not aim to elicit (more) pain. Finally, articles had to be written in English, Dutch, French or German (See Table 1 for an overview of the eligibility criteria).

As presented in Figure 1, the systematic search yielded 217 unique articles. The first phase of eligibility screening resulted in 22 citations. Hand-searching the reference lists of these articles did not yield any additional articles. Screening the full-texts of the 22 articles resulted in nine articles to be included.

Two researchers (NG and SR) independently extracted relevant information from each article: (1) LBP group: type of LBP, number, age and gender of participants, (2) healthy group: number, age and gender of participants, (3) fMRI technique and somatosensory stimulus or motor task, (4) main group differences, (5) correlations and (6) remarks. The nine included studies showed 
great variability in terms of participant's characteristics, fMRI (analysis) techniques, studied regions-of-interest (ROIs) and used somatosensory stimuli and motor tasks (See Table 2).

Two researchers (NG and SR) independently assessed risk of bias in each study with the validated Downs and Black tool ${ }^{45}$ as recommended by The Cochrane Collaboration. The Downs and Black tool consists of 27 items rating reporting bias, external validity and internal validity and has high internal consistency and inter-rater reliability. ${ }^{46}$ Because this review only included observational studies, a modified version of the Downs and Black tool was employed. This modified version has been used in other reviews. ${ }^{47,48}$ Questions related to the validity of the methodological design associated with an intervention were omitted (items 4, 8, 9, 13, 14, 15, 17, 19, 23, 24, 26 and 27) and case-series and case studies were not assessed on items related to a control group (items 5, 21, 22 and 23). Differences in scoring were discussed until consensus was reached. Both reviewers gave equal scores in $91 \%$ of the cases (131/144). Scores ranged from 45 to $85 \%$ between studies (see Table 3). Most articles scored low on external validity, as they provided insufficient information on the representativeness of participants who were willing and eligible to participate. While the majority of studies controlled for confounding factors, e.g. by matching groups on age and gender, only a few reported whether patients with LBP and healthy controls were recruited from a similar population and during a similar period. Finally, no study indicated if they performed analyses that were not planned a priori. Hence, none received a score on 'data dredging'. 


\section{Decreased brain activation in regions involved in higher-order sensory processing and}

\section{motor control in low back pain}

Two task-related fMRI studies revealed that patients with chronic LBP showed decreased brain activation in S2 during the processing of simultaneously applied tactile and proprioceptive stimuli at the lumbar spine, ${ }^{39}$ and in supplementary motor area (SMA) and superior temporal gyrus (STG) during motor imagery of daily life activities. ${ }^{44}$ Additionally, one resting-state fMRI study demonstrated decreased resting-state FC in S1, SMA, M1 and cerebellar lobules IV-V in patients with non-specific LBP compared to healthy subjects. ${ }^{42}$ This decreased resting-state FC in $\mathrm{M} 1$ and cerebellar lobules IV-V correlated significantly with a worse sensorimotor performance (more time to perform five sit-to-stand-to-sit movements when blindfolded) in patients with LBP and healthy subjects combined. ${ }^{42}$

Above-mentioned brain regions are important in different aspects of sensorimotor control. S1 processes unimodal sensory signals and integrates them with motor signals to guide movement. ${ }^{49}$ S2 integrates bilateral, multimodal sensory inputs ${ }^{50}$ and is key in sensorimotor integration through its connections with premotor planning areas. ${ }^{51,52}$ The STG contributes to the kinesthetic perception of joint movements ${ }^{53,54}$, higher-order sensory integration, and the formation of a body schema. ${ }^{55-57}$ The SMA is crucial for adequate motor planning, ${ }^{58-61}$ whereas M1 controls movement execution by generating motor commands. Finally, the cerebellum is considered important for sensorimotor and postural control, ${ }^{62-64}$ as it co-ordinates the acquisition of sensory signals on which motor systems depend. ${ }^{62}$ 
Taken together, these results could suggest a reduced sensorimotor-related brain activation and decreased resting-state FC in higher-order sensory processing and motor regions in patients with LBP. In these studies, it was proposed that a decreased brain activation in these regions might negatively affect sensorimotor behavior in patients with LBP through e.g., a down-regulated higher-order processing of multimodal (e.g. tactile and proprioceptive) sensory signals originating in the spine, a disrupted body schema of the trunk and impoverished motor planning. ${ }^{39,44}$ However, Pijnenburg et al. (2015) were the only researchers who directly correlated functional brain outcomes with sensorimotor performance. Therefore, abovementioned putative mechanisms warrant further study.

\section{Cortical reorganization in the primary and secondary somatosensory cortices in low back} pain

Two studies revealed changes in the cortical representation of the lumbar spine in patients with long-lasting LBP. ${ }^{40,44}$ Lloyd et al. (2008) reported that patients with chronic LBP who show aberrant pain-related illness behavior displayed a medially shifted S1 activation during tactile vibration at the lower back compared to healthy controls and well-coping patients with $\mathrm{LBP}^{40}$ This was consistent with previous findings of a medially shifted lumbar spine representation in S1 in patients with chronic LBP compared to healthy subjects. ${ }^{65}$ Moreover, Hotz-Boendermaker et al. (2016) revealed that the cortical representations of three lumbar vertebrae in S2 (not in S1) was blurred in patients with chronic LBP, whereas clearly distinct representations in S2 were found in healthy subjects. ${ }^{44}$ The difference in findings of a reorganized lumbar spine representation in $\mathrm{S}^{40,65}$ compared to in $\mathrm{S} 2^{44}$ could be explained by the nature of the applied stimuli, i.e. painful $^{65}$ and intense ${ }^{40}$ versus non-painful ${ }^{44}$. 
Taken together, these findings might suggest a reorganized lumbar spine representation in S1 and S2 in patients with chronic LBP. Bearing in mind that these regions are important for (multi)sensory processing, ${ }^{49,50}$ these results might corroborate behavioral findings of an impaired trunk perception and reduced lumbosacral tactile and proprioceptive acuity in patients with LBP. ${ }^{16,18,20,29}$ Moreover, since adequate sensory processing and integration are indispensable for optimal motor control, ${ }^{26-28}$ a reorganized lumbar spine representation may disturb spinal and postural control in patients with LBP. However, none of the studies above assessed trunk perception, tactile sensitivity, proprioceptive acuity or motor control. Consequently, direct conclusions on the behavioral implications of a reorganized trunk representation in S1 and S2 in LBP cannot be drawn.

\section{Increased brain activation in low back pain as maladaptive response}

Four task-related and two resting-state fMRI studies revealed patterns of increased sensorimotor-related brain activation in patients with LBP. ${ }^{36,38,40-42,44}$ Interestingly, these patterns were found in studies using a whole-brain approach ${ }^{40,41}$ and studies using predefined ROIs during fMRI analysis. ${ }^{38,42,44}$

Patients with chronic LBP showed increased brain activation during the appliance of pressure on their thumbnail in contralateral S1, bilateral S2 and ipsilateral inferior parietal lobule and cerebellum compared to healthy controls, who only activated S2 contralaterally. ${ }^{38}$ Moseley (2004a) reported a similar result in his case study, where a patient with chronic LBP displayed widespread activation in $\mathrm{S} 1, \mathrm{ACC}$, insula, parietal association areas and frontal cortices during 
abdominal muscle contractions. Furthermore, patients with chronic LBP exhibited widespread increased FC during motor imagery of daily life activities across the majority of the motor imagery network compared to healthy controls. ${ }^{44}$ This network consisted of left SMA, inferior parietal lobule and thalamus and bilateral M1, superior parietal lobules, supramarginal gyri, putamina, middle and inferior frontal gyri and insulae ${ }^{66}$ Interestingly, no group differences were found in a control region, suggesting that the increased motor imagery-driven FC in LBP was task-specific and not due to an overall enhanced FC. ${ }^{44}$ Additionally, patients with non-specific LBP demonstrated increased resting-state FC in lobule VI of the cerebellar vermis and right superior and middle frontal gyri compared to healthy subjects. ${ }^{42}$ Finally, compared to elderly with non-disabling chronic LBP, elderly with disabling chronic LBP exhibited increased restingstate FC in the medial prefrontal cortex. ${ }^{36}$

Up to now, it remains unclear whether these patterns of increased brain activity in LBP indicate (1) a diffuse, non-specific recruitment of brain regions during task performance due to loss of neural specialization (i.e. "dedifferentiation") ${ }^{67,68}$ or (2) a compensatory increase in brain activation to support performance ${ }^{69-71}$. Results from Moseley (2004a) support the "dedifferentiation" hypothesis. In this study, contracting specific abdominal muscles initially induced widespread brain activation. ${ }^{41}$ Interestingly, this motor-evoked activation reduced markedly after the patient received pain physiology education, although quality of task performance remained unchanged. ${ }^{41}$ This might suggest that the initially diffuse over-activation was non-functional and irrelevant for performing the motor task.

In contrast, results of Vrana et al. (2015) may support the second "compensation" hypothesis. In this study, patients with LBP showed diffusely spread increases in motor imagery-driven FC 
compared to pain-free controls. ${ }^{44}$ However, motor imagery performance did not differ between groups, suggesting that, although patients with LBP had retained their ability to perform motor imagined movements, they needed extra neural resources to preserve performance compared to controls. $^{44}$

Compensatory increases in brain activation may initially be adaptive. This was evident in the study of Lloyd et al. (2008). They revealed that well-coping patients with chronic LBP activated the right PCC and left posterior parietal lobe more during intense tactile stimulation at the lumbar spine compared to patients with chronic LBP showing abnormal pain-related illness behavior. ${ }^{40}$ Interestingly, this increased sensory-evoked activation correlated significantly with lower levels of catastrophizing in the well-coping patients, suggesting a neural mechanism of successful adjustment to and coping with pain. ${ }^{40}$ However, compensatory mechanisms of overactivation may become maladaptive over time, thereby potentially leading to sensorimotor impairments. This was suggested by Buckalew et al. (2010), who showed an increased restingstate FC in the medial prefrontal cortex in elderly with disabling chronic LBP compared to peers with non-disabling chronic LBP. The medial prefrontal cortex is suggested to be involved in expectation and top-down inhibition of negative emotions ${ }^{72-74}$ and inhibits motor planning areas when activated. ${ }^{75}$ The authors suggested that suppressing negative emotions and expectations of pain in patients with disabling chronic LBP could activate the medial prefrontal cortex, thereby inhibiting motor planning and inducing disability over time. ${ }^{36}$

Unfortunately, none of the studies mentioned above decisively showed whether the increased brain activation patterns in LBP indicate a dedifferentiated brain activation during sensorimotor processing or a compensatory increase in brain activity to preserve sensorimotor behavior. This 
question could be solved by correlating functional brain outcomes with sensorimotor behavior, with positive correlations indicating a compensatory increased brain activation and negative correlations supporting the dedifferentiation hypothesis. ${ }^{71}$ However, only two included studies correlated brain function (i.e. resting-state FC) with sensorimotor behavior, respectively in patients with LBP and healthy controls combined, and in elderly with disabling and nondisabling chronic LBP combined. ${ }^{36,44}$ Thus, more studies that directly correlate functional brain outcomes with sensorimotor behavior in patients with LBP are urgently needed to elucidate the neural correlates of sensorimotor impairments in LBP. For instance, studying brain activation during the processing of proprioceptive signals (e.g., by applying muscle vibration during $\mathrm{fMRI}^{76}$ ) and correlating this with proprioceptive use during postural control, could clarify the neural underpinnings of postural control deficits in patients with LBP.

Neuroimaging studies could also unravel the causal relationship between sensorimotor-related brain changes and LBP. Unfortunately, all included studies were cross-sectional. Moreover, only two of the nine studies investigated, and did not find, correlations between brain function (i.e. resting-state FC) and duration of LBP (total amount of months with LBP) ${ }^{36}$, and between sensorimotor performance and LBP intensity. ${ }^{44}$ Therefore, until confirmed by longitudinal research, a bidirectional relationship between functional brain changes and LBP can be hypothesized. First, ongoing LBP might lead to maladaptive, widespread brain changes that could predispose patients to further pain chronification. Alternatively, sensorimotor-related brain changes might already be present prior to the emergence of $\mathrm{LBP}^{77}$ For example, altered brain activation patterns in regions involved in higher-order sensory processing and motor planning, present prior to LBP, might negatively affect trunk movement patterns, thereby inducing hyper- 
or hypo-activity of trunk muscles. ${ }^{78}$ Such suboptimal trunk movement patterns may in turn lead to excessive lumbar movements beyond the normal range of mechanical stability, ${ }^{79}$ abnormal loading of the lumbar spine and (recurrence of) LBP. A recent longitudinal behavioral study supports this latter causal direction. ${ }^{13}$ In this study, young pain-free individuals who predominantly used ankle muscle proprioception instead of lumbosacral proprioceptive signals during postural control showed an increased risk of developing or maintaining LBP within two years. ${ }^{13}$ However, longitudinal neuroimaging studies that directly investigate associations between brain function, sensorimotor behavior and LBP are highly needed to clarify the causality between sensorimotor-related functional brain changes and LBP.

\section{Do we need to think outside the "pain matrix" box when observing individuals with low back pain?}

Three included studies used the "pain matrix" concept to design the experiments, analyze the obtained fMRI data and/or interpret study results. ${ }^{37,38,41}$ The "pain matrix" has been described as a network of brain areas that are involved in different aspects of pain perception, such as sensory-discriminative aspects (S1, S2, insula, thalamus), affective-attentional aspects (amygdala, ACC, posterior parietal and prefrontal cortices), motor responses to pain (SMA, cerebellum, striatum) and top-down inhibition of pain (periaqueductal gray) (for reviews, see $\left.{ }^{80,81}\right)$. In the past, researchers have proposed that the conscious perception of pain arises from "pain matrix" activity during the processing of nociceptive inputs. ${ }^{80,81}$ Some authors even suggested to use "pain matrix" activity to objectively measure whether or not patients actually

experience pain. ${ }^{82}$ However, caution might be needed when using the "pain matrix" concept to set up experiments, analyze and interpret fMRI data in LBP research. 
For example, some studies considered LBP as the result of persistent abnormal pain processing, similar to e.g., fibromyalgia and irritable bowel syndrome. This might have influenced the experimental set-up and fMRI analysis. For instance, Giesecke et al. (2004) and Gay et al. (2014) narrowed their search volume to only "pain-related" brain regions. They based their selection on a previous study on pressure pain sensitivity in healthy subjects ${ }^{83}$ and previous fMRI studies showing increased brain responses to painful stimuli in patients with $\mathrm{LBP}^{32,84}$, respectively. However, as many of these "pain-related" regions are also shown to play an important role in sensorimotor control (e.g. $\mathrm{S}^{49} ; \mathrm{S} 2^{50-52}$; M1; $\mathrm{SMA}^{58,59,61}$; cerebellum ${ }^{62}$; $\mathrm{STG}^{53,54}$ ), they cannot be viewed as merely "pain-specific" regions. This was evident in some of the included studies. While Giesecke et al. (2004) and Gay et al. (2014) considered SMA, M1, inferior parietal lobule, thalamus, basal ganglia, middle frontal gyrus and insula as "pain-related", two other studies viewed the same regions as "sensorimotor-related". 39,44 Therefore, findings of increased sensoryor motor-evoked brain activation in these brain regions in patients with LBP might suggest an altered sensorimotor processing in LBP, in addition to abnormal pain processing.

Second, new insights support that the functional significance of the "pain matrix" needs to be reinterpreted (for reviews, see ${ }^{85,86}$ ). For instance, studies showed that several "pain matrix" regions are not solely activated during nociceptive stimulation, but also during non-nociceptive somatosensory, auditory and visual stimulation (e.g., S2, insula and ACC). ${ }^{87}$ This indicates that any type of stimulus, independent of the modality, can elicit the majority of brain responses to nociceptive stimuli. ${ }^{87}$ Moreover, "pain matrix" responses to nociceptive stimuli are larger when the presented stimuli are novel and unpredictable. ${ }^{88}$ Finally, patients with congenital analgesia 
(or insensitivity to pain) appear to activate the same "pain matrix" regions as healthy subjects during the presentation of noxious stimuli that were perceived as painful by the healthy subjects. $^{89}$

Taken together, these recent findings suggest that the "pain matrix" does not merely present a cortical representation of pain. However, it might serve as a defensive salience detection system that detects, processes, orients attention towards and reacts upon salient sensory inputs. ${ }^{85,86}$ As such, both nociceptive and non-nociceptive stimuli could trigger responses in the salience detection system if their salience content is sufficiently high, e.g. because they contrast greatly from their surroundings, are entirely new or diverge from expectations based on previous experiences. ${ }^{85,86}$

Thus, findings of increased sensorimotor-evoked brain activation within regions of the so-called "pain matrix" in LBP might need to be reappraised. Giesecke et al. (2004) interpreted increased sensory-evoked brain activation in S1, S2, inferior parietal lobule and cerebellum (parts of the "pain matrix") in patients with LBP as "augmented pain processing", although the sensory stimuli were non-noxious and applied at a pain-free body site (thumbnail). Moreover, Moseley (2004a) stated that abdominal muscle contractions activated regions of the "pain matrix" (S1, ACC, insula, parietal and frontal cortices) in a patient with LBP, even though she did not perceive the motor task as painful. Taken together, these findings of increased sensorimotorevoked brain activation may indicate that patients with LBP are over-responsive/over-attentive towards salient sensory inputs that signal possibly back-threatening events and require action, thereby inducing over-generalized motor responses to protect the spine. Such protective responses have been identified in patients with LBP, i.e. they appeared to over-activate lumbar 
paravertebral and abdominal muscles during normal trunk and limb movements and during walking. ${ }^{78,90-92}$ Protective motor responses may initially be adaptive. However, they often lose their protective function over time, e.g., through a vicious cycle of decreased lumbar movement and increased muscular stress, which induces (more) pain and disability and reduces physical activity further. ${ }^{93}$ Recent work supports that increased brain responses to non-nociceptive stimuli, leading to over-generalized protective motor responses, may induce LBP. ${ }^{77}$ However, longitudinal studies are highly needed to clarify the causality between sensorimotor-related functional brain changes and LBP. Such studies could also help to optimize LBP management, which nowadays mainly targets symptoms and musculoskeletal dysfunctions (vs. addressing brain changes) with e.g., massage, lumbar traction or manipulation, but has no to only smallmodest effects (e.g. reviews ${ }^{94-97}$ ).

\section{Targeting functional brain changes in patients with low back pain with therapy}

The included studies revealed overall that patients with LBP display altered patterns of brain activation related to somatosensory processing and motor performance. Interestingly, studies have shown that maladaptive functional brain changes are reversible with treatment (e.g., with motor training) ${ }^{98,99}$ Therefore, more efforts are being made to develop interventions that target brain changes in patients with LBP. The current review on the association between functional brain changes and sensorimotor behavior in patients with LBP may provide additional insights into which interventions could be valuable in the management of LBP.

First, performing motor-imagined movements might help to restore disrupted brain activation patterns in LBP. $^{44}$ Motor imagery activates largely the same brain regions as motor 
execution $^{100,101}$ without requiring the patient to actually perform the movements. Therefore, it can be particularly advantageous in anxious or fearful patients. Motor imagery has already been proven effective to improve trunk dynamics in ballet dancers with $\mathrm{LBP},{ }^{102}$ and to diminish pain and to improve movement in patients after lumbar surgery. ${ }^{103}$ However, future studies investigating the effect of graded motor imagery training on brain activation patterns in patients with LBP are needed. Moreover, studying the effect of "kinesthetic imagery" (imaging the sensations of muscular contraction, relaxation and stretching during specific movements) in patients with LBP might be valuable. ${ }^{104}$

Second, Moseley (2004a) highlighted the potential of pain physiology education to normalize brain activation during motor performance (e.g., by reducing the perceived threat related to the motor $\operatorname{task}^{41)}$ in addition to its proven effect on reducing pain and improving physical performance in LBP. ${ }^{105}$

Third, the importance of improving pain coping strategies in patients with LBP was revealed by Lloyd et al. (2008). In this study, well-coping patients with chronic LBP showed increased sensory-evoked brain activation in PCC and posterior parietal lobe, which correlated with lower catastrophizing scores. ${ }^{40}$ In contrast, patients with chronic LBP who showed poor pain coping were not able to activate these brain regions, and reported higher current pain scores and higher levels of catastrophizing and depression. ${ }^{40}$ Coping strategies can be improved with cognitive behavioral therapy, which has already been proven effective on the long-term in patients with non-specific LBP. ${ }^{106}$

In addition to above-mentioned strategies, other top-down and bottom-up interventions have been shown promising to improve pain and function and normalize brain changes in patients 
with LBP (for recent reviews, see ${ }^{107-110}$ ). For example, specific motor control training of trunk muscles normalized cortical reorganization in $\mathrm{M} 1$ and trunk muscle recruitment patterns in patients with $\mathrm{LBP},{ }^{99}$ while sensory discrimination training (or recognizing the location and type of different stimuli) significantly improved pain and functioning in LBP. ${ }^{108}$ Moreover, peripheral magnetic stimulation of deep abdominal muscles restored M1 intracortical inhibition mechanisms and improved postural control in LBP. ${ }^{111}$ Finally, well-considered combinations of different top-down and bottom-up interventions may yield additive effects in the treatment of LBP. For example, providing education on pain physiology prior to specific motor control exercises may reduce cortical over-activation during the exercises. ${ }^{41}$ Peripheral electrical stimulation combined with transcranial direct current stimulation over M1, or combining peripheral magnetic stimulation of trunk muscles with motor control training might reduce pain more and improve motor learning. ${ }^{11,112}$ However, further studies are imperative to optimize the evidence-based management of LBP.

\section{Methodological considerations and future studies}

The following section discusses methodological considerations regarding functional brain research in LBP, including the recruitment of participants, the preprocessing of resting-state fMRI data, the added value of combining structural and functional brain imaging techniques and the need for longitudinal studies.

First, only three studies accounted for possible confounding factors during the recruitment of participants. ${ }^{36,38,43}$ Buckalew et al. (2010) excluded individuals with disorders with well-known effects on brain function (e.g. diabetes, depression, anxiety or multiple sclerosis) and subjects 
who were or had been taking psychotropics. Giesecke et al. (2004) asked participants to discontinue the intake of antidepressants up to four weeks before the tests and excluded patients who were taking long-term opioid medication. Shi et al. (2015) only included participants who had no psychiatric illnesses or did not take any drugs within the last month. However, in the other six studies, medication use nor the presence of psychiatric/neurological disorders was questioned, despite a wealth of studies demonstrating their effect on brain function. ${ }^{113-116}$ Thus, future studies should screen participants more rigorously for confounding factors. Additionally, to obtain more homogenous groups of patients with ongoing LBP, researchers might also consider subgrouping individuals with LBP, e.g., based on recurrent versus chronic LBP. However, since considerable heterogeneity exists even within the subgroup of patients with chronic LBP (e.g. in terms of pain duration, psychosocial profile and potential underlying mechanisms), a more thorough clinical examination of patients with LBP prior to inclusion might be warranted.

Second, the preprocessing of resting-state fMRI data differed between studies. Gay et al. (2014) determined resting-state FC by calculating bivariate correlations between the time series of two ROIs, whereas Buckalew et al. (2010) used a seed-based approach. Pijnenburg et al. (2015) analyzed resting-state fMRI data with two different techniques: (1) independent component analysis that decomposed fMRI data into spatially independent resting-state networks ${ }^{117}$ of which the sensorimotor network was retained for final analysis and (2) FC density mapping to calculate long- and short-range FC density in the sensorimotor network ${ }^{118}$. The differences in preprocessing hampered the integration of findings on resting-state FC in LBP across studies. 
Third, only one study combined structural (high-resolution anatomical imaging and diffusion tensor imaging) and functional MRI techniques (resting-state fMRI) to investigate brain alterations in LBP. $^{36}$ Future studies incorporating different structural and functional neuroimaging techniques are imperative to improve our in-depth understanding of neural alterations associated with impaired sensorimotor behavior in patients with LBP.

Fourth, because of the relatively small number of participants in the included studies (ranging from one to 45), results should be generalized with caution.

Finally, future studies might consider using graph theory to analyze brain function and structure from a network perspective. Graph theory differs from more traditional approaches that examine individual components of the brain, such as cortical regions, by quantifying different topological properties of functional and structural brain networks. In this way, graph theory can be used to study the efficiency of information transfer between brain regions. To the best of the author's knowledge, only one study used graph theory, thereby revealing a disrupted white matter network organization (i.e. decreased local efficiency and increased connectivity degree in M1) in patients with non-specific LBP compared to healthy controls. ${ }^{119}$ Moreover, this study showed a significant correlation between decreased global efficiency and a worse sensorimotor performance in the patients with LBP. ${ }^{119}$

\section{Conclusions}

This review revealed the presence of functional brain changes associated with sensorimotor behavior and at rest in patients with long-lasting LBP compared to healthy subjects. Patients with LBP demonstrated decreased sensorimotor-evoked brain activation and a reorganized lumbar spine representation in brain regions involved in higher-order sensory processing and motor 
control compared to healthy subjects. These results could support behavioral findings of a disturbed body schema of the trunk, reduced lumbosacral tactile and proprioceptive acuity, impaired sensorimotor performance and postural control deficits in LBP. Additionally, patients with LBP showed widespread increases in brain activation during non-nociceptive external (i.e. pressure) as well as bodily-induced stimuli (i.e. motor tasks) in regions of the so-called "painmatrix". In the past, these findings were often interpreted as abnormal pain processing in LBP. However, findings of this review support an urgent need to reinterpret these results. Specifically, they may indicate that patients with long-lasting LBP are over-responsive to sensory inputs that potentially signal danger to the body, thereby inducing maladaptive, over-generalized motor responses to protect the spine. Hence, functional brain changes associated with sensorimotor behavior may lead to (recurrences of) LBP. However, longitudinal studies are crucial to elucidate the causality between functional brain changes, sensorimotor behavior and LBP and to investigate the effect of targeted training interventions addressing these specific brain changes in patients with LBP. 


\section{References}

- Walker BF. The prevalence of low back pain: a systematic review of the literature from 1966 - 1998. J Spinal Disord 2000; 13(3): 205-17.

- Hoy D, Bain C, Williams G, et al. A systematic review of the global prevalence of low back pain. Arthritis Rheumatol 2012; 64(6): 2028-37.

- Hestbaek L, Leboeuf-Yde C, Manniche C. Low back pain: what is the long-term course? A review of studies of general patient populations. Eur Spine J 2003; 12(2): 149-65.

- Pengel LHM, Herbert RD, Maher CG, Refshauge KM. Acute low back pain: systematic review of its prognosis. $B M J 2003 ; 327(7410): 323$.

- Itz CJ, Geurts JW, Kleef M, Nelemans P. Clinical course of non-specific low back pain: a systematic review of prospective cohort studies set in primary care. Eur J Pain 2013; 17(1): $5-15$.

- Dunn KM, Hestbaek L, Cassidy JD. Low back pain across the life course. Best Pract Res Clin Rheumatol 2013; 27(5): 591-600.

- Meucci RD, Fassa AG, Faria NM. Prevalence of chronic low back pain: systematic review. Rev Saude Publica 2015; 49: PMC4603263.

- Vos T, Flaxman AD, Naghavi M, et al. Years lived with disability (YLD's) for 1160 sequelae of 289 diseases and injuries 1990-2010: a systematic analysis for the Global Burden of Disease Study 2010. Lancet 2012; 380: 2163-96.

- Hoy D, March L, Brooks P, et al. Global burden of low back pain: estimates from the Global Burden of Disease 2010 study. Ann Rheum Dis 2014; 73: 968-74. 
- Airaksinen O, Brox JI, Cedraschi C, et al. Chapter 4 European guidelines for the management of chronic nonspecific low back pain. Eur Spine J 2004; 15 (Suppl. 2): S192S300.

- Costa LCM, Koes BW, Pransky G, et al. Primary care research priorities for low back pain: an update. Spine 2013; 38(2): 148-56.

- van Dieën J, Moseley GL, Hodges PW. Chapter 18: Motor control changes and low back pain: Cause or effect? In Hodges PW, Cholewicki J, Van Dieën JH, eds. Spinal control: the rehabilitation of back pain. State of the art and science. Edinburgh: Elsevier; 2013: 219-30.

- Claeys K, Dankaerts W, Janssens L, et al. Young individuals with a more ankle-steered proprioceptive control strategy may develop mild non-specific low back pain. $J$ Electromyogr Kinesiol 2015; 25(2): 329-38.

- Bray H, Moseley GL. Disrupted working body schema of the trunk in people with back pain. Br J Sports Med 2011; 45; 168-73.

- Bowering KJ, Butler DS, Fulton IJ. Motor imagery in people with a history of back pain, current pain, both, or neither. Clin J Pain 2014; 30: 1070-5.

- Brumagne S, Cordo P, Lysens R, Verschueren S, Swinnen S. The role of paraspinal muscle spindles in lumbosacral position sense in individuals with and without low back pain. Spine 2000; 25(8): 989-94.

- Wand BM, Di Pietro F, George P, O'Connell NE. Tactile thresholds are preserved yet complex sensory function is impaired over the lumbar spine of chronic non-specific low back pain patients: a preliminary investigation. Physiotherapy 2010; 96(4): 317-23.

- Luomajoki H, Moseley GL. Tactile acuity and lumbopelvic motor control in patients with low back pain and healthy controls. Br J Sports Med 2011; 45: 437-40. 
- Boucher JA, Abboud J, Nougarou F, Normand MC, Descarreaux M. The effects of vibration and muscle fatigue on trunk sensorimotor control in low back pain patients. PLOS ONE 2015; 10(8): e0135838.

- Tong MH, Mousavi SJ, Kiers H, Ferreira P, Refshauge K, van Dieën J. Is there a relationship between lumbar proprioception and low back pain? A systematic review with meta-analysis. Arch Phys Med Rehabil 2016: 98(1): 120-36.

- Brumagne S, Cordo P, Verschueren S. Proprioceptive weighting changes in persons with low back pain and elderly persons during upright standing. Neurosci Lett 2004; 366(1): 63-6.

- Brumagne S, Janssens L, Knapen S, Claeys K, Suuden-Johanson E. Persons with recurrent low back pain exhibit a rigid postural control strategy. Eur Spine J 2008; 17(9): 1177-84.

- Claeys K, Brumagne S, Dankaerts W, Kiers H, Janssens L. Decreased variability in postural control strategies in young people with non-specific low back pain is associated with altered proprioceptive weighting. Eur J Appl Physiol 2011; 111(1): 115-23.

- Mazaheri M, Coenen P, Parnianpour M, Kiers H, van Dieën JH. Low back pain and postural sway during quiet standing with and without sensory manipulation: a systematic review. Gait Posture 2013; 37: 12-22.

- Claeys K, Dankaerts W, Janssens L, Brumagne S. Altered preparatory pelvic control during the sit-to-stance-to-sit movement in people with non-specific low back pain. J Electromyogr Kinesiol 2012; 22: 821-828.

- Lackner JR, Dizio P. Vestibular, proprioceptive, and haptic contributions to spatial orientation. Аппи Rev Psychol 2005; 56: 115-47.

- Carver S, Kiemel T, Jeka JJ. Modeling the dynamics of sensory reweighting. Biol Cybern 2006; 95: 123-34. 
- Chiba R, Takakusaki K, Ota J, Yozu A, Haga N. Human upright posture control models based on multisensory inputs, in fast and slow dynamics. Neurosci Res 2016; 104: 96-104.

- Wand BM, Parkitny L, O'Connell NE, et al. Cortical changes in chronic low back pain: current state of the art and implications for clinical practice. Man Ther 2011; 16(1): 15-20.

- Kregel J, Meeus M, Malfliet A, et al. Structural and functional brain abnormalities in chronic low back pain: a systematic review. Semin Arthritis Rheum 2015; 45(2): 229-237.

- Giesecke T, Gracely, RH, Clauw DJ, et al. Central pain processing in chronic low back pain. Evidence for reduced pain inhibition. Schmerz 2006; 20(5): 411-4, 416-7.

- Kobayashi Y, Kurata J, Sekiguchi M, et al. Augmented cerebral activation by lumbar mechanical stimulus in chronic low back pain patients: an fMRI study. Spine 2009; 34(22): 2431-2436.

- Callan D, Mills L, Nott C, England R, England S. A tool for classifying individuals with chronic back pain: using multivariate pattern analysis with functional magnetic resonance imaging data. PLoS ONE 2014, 9(6), e98007.

- Lloyd DM, Findlay G, Roberts N, Nurmikko T. Illness behavior in patients with chronic low back pain and activation of the affective circuitry of the brain. Psychosom Med 2014; 76(6): 413-21.

- Moher D, Liberati A, Tetzlaff J, Altman D G \& The PRISMA Group. Preferred reporting items for systematic reviews and meta-analyses: The PRISMA statement. PLoS Med 2009; 6(6): e1000097.

- Buckalew N, Haut MW, Aizenstein H, et al. Differences in brain structure and function in older adults with self-reported disabling and nondisabling chronic low back pain. Pain Med 2010; 11(8): 1183-97. 
- Gay CW, Robinson ME, George SZ, Perlstein WM, Bishop MD. Immediate changes after manual therapy in resting-state functional connectivity as measured by functional magnetic resonance imaging in participants with induced low back pain. $J$ Manipulativ Physio Ther 2014; 37: 614-27.

- Giesecke T, Gracely RH, Grant MAB, et al. Evidence of augmented central pain processing in idiopathic chronic low back pain. Arthritis Rheumatol 2004; 50(2): 613-23.

- Hotz-Boendermaker S, Marcar VL, Meier ML, Boendermaker B, Humphreys BK. Reorganization in secondary somatosensory cortex in chronic low back pain patients. Spine 2016; 41(11): E667-E673.

- Lloyd DM, Findlay G, Roberts N, Nurmikko T. Differences in low back pain behavior are reflected in the cerebral response to tactile stimulation of the lower back. Spine 2008; 33(12): $1372-7$.

- Moseley GL. Widespread brain activity during an abdominal task markedly reduced after pain physiology education: fMRI evaluation of a single patient with chronic low back pain. Aust J Physiother 2004a; 51: 49-52.

- Pijnenburg M, Brumagne S, Caeyenberghs K, et al. Resting-state functional connectivity of the sensorimotor network in individuals with nonspecific low back pain and the association with the sit-to-stand-to-sit task. Brain Connect 2015; 5(5): 303-311.

- Shi Y, Liu Z, Zhang S, et al. Brain network response to acupuncture stimuli in experimental acute low back pain: an fMRI study. Evid Based Complement Alternat Med 2015; 2015 : 210120. 
- Vrana A, Hotz-Boendermaker S, Stämpfli P, et al. Differential neural processing during motor imagery of daily activities in chronic low back pain patients. PLOS ONE 2015; 10(11): e0142391.

- Reeves BC, Deeks JJ, Higgins J, George A. Including non-randomized studies. In: Higgins J, Green S, eds. Cochrane Handbook for Systematic Reviews of Interventions 5.0.1. Chichester, United Kingdom: John Wiley \& Sons Ltd; 2008: 391-432.

- Downs SH, Black N. The feasibility of creating a checklist for the assessment of the methodological quality both of randomized and non-randomised studies with health care interventions. J Epidemiol Community Health 1998; 52(6): 377-84.

- Irving DB, Cook JL, Menz HB. Factors associated with chronic plantar heel pain: a systematic review. J Sci Med Sport 2006; 9(1-2): 11-22.

- Munna J, Sullivan SJ, Schneiders AG. Evidence of sensorimotor deficits in functional ankle instability: A systematic review with meta-analysis. J Sci Med Sport 2010; 13(1): 2-12.

- Borich MR, Brodie SM, Gray WA, Ionta S, Boyd LA. Understanding the role of the primary somatosensory cortex: opportunities for rehabilitation. Neuropsychologia 2015, 79(B): 24655.

- Chen TL, Babiloni C, Ferretti A, et al. Human secondary somatosensory cortex is involved in the processing of somatosensory rare stimuli: an fMRI study. Neuroimage 2008; 40(4): $1765-71$.

- Kaas JH. Evolution of somatosensory and motor cortex in primates. Anat Rec A Discov Mol Cell Evol Biol 2004; 281: 1148-56. 
- Hinkley B, Krubitzer LA, Nagarajan SS, Disbrow EA. Sensorimotor integration in S2, PV, and parietal rostroventral areas of the human sylvian fissure. J Neurophysiol 2007; 97: 128897.

- Kavounoudias A, Roll JP, Anton JL, Nazarian B, Roth M, Roll R. Proprio-tactile integration for kinesthetic perception: an fMRI study. Neuropsychologia 2008; 46: 567-75

- Kenzie JM, Semrau JA, Findlater SE, et al. Localization of impaired kinesthetic processing post-stroke. Front Hum Neurosci 2016; 10: 505.

- Boussaoud D, Ungerleider LG, Desimone R. Pathways for motion analysis: cortical connections of the medial superior temporal and fundus of the superior temporal visual areas in the macaque. J Comp Neurol 1990; 296: 462-95.

- Caspers S, Zilles K, Laird AR, Eickhoff SB. ALE meta-analysis of action observation and imitation in the human brain. Neuroimage 2010; 50: 1148-67.

- Herrington JD, Nymberg C, Schultz RT. Biological motion task performance predicts superior temporal sulcus activity. Brain Cogn 2010; 77: 372-81.

- Nachev P, Kennard C, Husain M. Functional role of the supplementary and presupplementary motor areas. Nature Rev Neurosci 2008; 9: 856-69.

- Jacobs JV, Lou JS, Kraakevik JA, Horak JB. The supplementary motor area contributes to the timing of the anticipatory postural adjustments during step initiation in participants with and without Parkinson's disease. Neuroscience 2009; 164: 877-85.

- Mihara M, Miyai I, Hatakenaka JA, Kubota K, Sakoda S. Role of the prefrontal cortex in human balance control. Neuroimage 2008; 41: 1021-31.

- Herold F, Orlowski K, Börmel S, Notger C. Cortical activation during balancing on a balance board. Hum Mov Sci 2017; 51: 51-8. 
- Manto M, Bower JM, Conforto AB, et al. Consensus paper: roles of the cerebellum in motor control - the diversity of ideas on cerebellar involvement in movement. Cerebellum 2012; 11(2): 457-87.

- Stoodley CJ, Valera EM, Schmahmann JD. Functional topography of the cerebellum for motor and cognitive tasks: an fMRI study. Neuroimage 2012; 59: 1560-70.

- Zwergal A, Linn J, Xiong G, Brandt T, Strupp M, Jahn K. Aging of human supraspinal locomotor and postural control in fMRI. Neurobiol Aging 2012; 33: 1073-84.

- Flor H, Braun C, Elbert T, Birbaumer N. Extensive reorganization of primary somatosensory cortex in chronic back pain patients. Neurosci Lett 1997; 224(1): 5e8.

- Hétu S, Gregoire M, Saimpont A, et al. The neural network of motor imagery: an ALE metaanalysis. Neurosci Biobehav Rev 2013; 37: 930-49.

- Li SC, Lindenberger U, Sikström S. Aging cognition: from neuromodulation to representation. Trends Cogn Sci 2001; 5(11): 479-86.

- Carp J, Park J, Hebrank A, Park DC, Polk TA. Age-related neural dedifferentiation in the motor system. PLoS ONE 2011; 6(12): e29477.

- Ward NS, Frackowiak RSJ. Age-related changes in the neural correlates of motor performance. Brain 2013; 126: 873-88.

- Ward NS. Compensatory mechanisms in the aging motor system. Ageing Res Rev 2006; 5: 239-54.

- Heuninckx S, Wenderoth N, Swinnen SP. Systems neuroplasticity in the aging brain: recruiting additional resources for successful motor performance in elderly persons. $J$ Neurosci 2008; 28(1): 91-9. 
- Goldin PR, McRae K, Ramel W, Gross JJ. The neural bases of emotion regulation: reappraisal and suppression of negative emotion. Biol Psychiatry 2008; 63: 577-86.

- Phan KL, Fitzgerald DA, Nathan PJ, Moore GJ, Uhde TW, Tancer ME. Neural substrates for voluntary suppression of negative affect: a functional magnetic resonance imaging study. Biol Psychiatry 2005; 57: 210-9.

- Bermpohl F, Pascual-Leone A, Amedi A, et al. Attentional modulation of emotional stimulus processing: an fMRI study using emotional expectancy. Hum Brain Mapp 2006; 27: 662-77.

- Davis H IV, Liotti M, Ngan E, et al. fMRI BOLD signal changes in elite swimmers while viewing videos of personal failure. Brain Imaging Behav 2008; 2: 84-93.

- Goossens N, Janssens L, Pijnenburg M, et al. Test-retest reliability and concurrent validity of a fMRI-compatible pneumatic vibrator to stimulate muscle proprioceptors. Multisens Res 2016; 29: 465-92.

- Moseley GL, Vlaeyen JW. Beyond nociception: the imprecision hypothesis of chronic pain. Pain 2015; 156(1): 35-8.

- van Dieën JH, Selen LP, Cholewicki J. Trunk muscle activation in low-back pain patients, an analysis of the literature. J Electromyogr Kinesiol 2003; 13: 333-51.

- Cholewicki J, McGill SM. Mechanical stability of the in vivo lumbar spine: implications for injury and chronic low back pain. Clin Biomech 1996; 11(1): 1-15.

- Peyron R, Laurent B, Garcia-Larrea L. Functional imaging of brain responses to pain. A review and meta-analysis. Clin Neurophysiol 2000; 30: 263-88.

- Fenton BW, Shih E, Zolton J. The neurobiology of pain perception in normal and persistent pain. Pain Manag 2015, 5(4), 287-317. 
- Borsook D, Sava S, Becerra L. The pain imaging revolution: advancing pain into the $21^{\text {st }}$ century. Neuroscientist 2010; 16: 171-85.

- Gracely RH, Petzke F, Grant MAB, et al. Symmetrical and lateralized supraspinal responses to bilateral painful blunt pressure [abstract]. Proceedings of the Society for Neuroscience 30th Annual Meeting, 2000; New Orleans: 441

- Baliki MN, Petre B, Torbey S, et al. Corticostriatal functional connectivity predicts transition to chronic back pain. Nat Neurosci 2012; 15(8): 1117-9.

- Iannetti GD, Mouraux A. From the neuromatrix to the pain matrix (and back). Exp Brain Res 2010; 205: 1-12.

- Legrain V, Iannetti GD, Plaghki L, Mouraux A. The pain matrix reloaded. A salience detection system for the body. Prog Neurobiol 2011; 93: 111-24.

- Mouraux A, Diukova A, Lee MC, Wise RG, Iannetti GD. A multisensory investigation of the functional significance of the "pain matrix". Neuroimage 2011; 54(3): 2237-49.

- Iannetti GD, Hughes NP, Lee MC, Mouraux A. Determinants of laser-evoked EEG responses: pain perception or stimulus saliency? J Neurophysiol 2008; 100: 815-28.

- Salomons TV, Iannetti GD, Liang M, Wood JN. The pain matrix in pain-free individuals. JAMA Neurology 2016; 73(6): 755-6.

- Macdonald DA, Dawson AP, Hodges PW. Behavior of the lumbar multifidus during lower extremity movements in people with recurrent low back pain during symptom remission. $J$ Orthoped Sports Phys Ther 2011; 41: 155-64.

- Massé-Alarie H, Beaulieu LD, Preuss R, Schneider C. Influence of chronic low back pain and fear of movement on the activation of the transversely oriented abdominal muscles during forward bending. J Electromyogr Kinesiol 2016b; 27: 87-94 
- Pakzad M, Fung J, Preuss R. Pain catastrophizing and trunk muscle activation during walking in patients with chronic low back pain. Gait Posture 2016; 49: 73-7.

- Langevin HM, Sherman KJ. Pathophysiological model for chronic low back pain integrating connective tissue and nervous system mechanisms. Med Hypotheses 2007; 68: 74-80.

- Rubinstein SM, Terwee CB, Assendelft WJJ, de Boer MR, van Tulder MW. Spinal manipulative therapy for acute low back pain: an update of the Cochrane review. Cochrane Database Syst Rev 2013; 38(3): E158-77.

- Wegner I, Widyahening IS, van Tulder MW et al. Traction for low-back pain with or without sciatica. Cochrane Database Syst Rev 2013; 8: CD003010.

- Furlan AD, Giraldo M, Baskwill A, Irvin E, Imamura M. Furlan, A.D. Massage for low-back pain. Cochrane Database Syst Rev 2015; 9: CD00192915.

- Maher C, Underwood M, Buchbinder R. Non-specific low back pain. Lancet 2016; 389(10070): 736-47.

- Seminowicz DA, Wideman TH, Naso L, et al. Effective treatment of chronic low back pain in humans reverses abnormal brain anatomy and function. J Neurosci 2011;31(20): 7540-50.

- Tsao H, Druitt TR, Schollum TM, Hodges PW. Motor training of the lumbar paraspinal muscles induces immediate changes in motor coordination in patients with recurrent low back pain. J Pain 2010b; 11(11): 1120-8.

- Jeannerod M, Frak V. Mental imaging of motor activity in humans. Curr Opin Neurobiol 1999; 9, 735-9.

- Kraeutner S, Gionfriddo A, Bardouille T, Boe S. Motor imagery-based brain activity parallels that of motor execution: evidence from magnetic source imaging of cortical oscillations. Brain Res 2014; 1558: 81-91. 
- Gildea JE, Van Den Hoorn W, Hides JA, Hodges PW. Trunk dynamics are impaired in ballet dancers with back pain but improve with imagery. Med Sci Sports Exerc 2015; 47: 16651671.

- Louw A, Schmidt SG, Louw C, Puentedura EJ. Moving without moving: immediate management following lumbar spine surgery using a graded motor imagery approach: a case report. Physiother Theory Pract 2015; 31: 509-17.

- Brumagne S, Dolan T, Pickar J. What is the relation between proprioception and low back pain? In Hodges PW, Cholewicki J, Van Dieën JH, eds. Spinal control: the rehabilitation of back pain. State of the art and science. Edinburgh: Elsevier; 2013; 219-230.

- Moseley GL. Evidence for a direct relationship between cognitive and physical change during an education intervention in people with chronic low back pain. Eur J Pain 2004; 8: $39-45$.

- Richmond H, Hall AM, Copsey B, et al. The effectiveness of cognitive behavioural treatment for non-specific low back pain: A systematic review and meta-analysis. PLOS ONE 2015; 10 : $1-20$.

- Daffada PJ, Walsh N, McCabe CS, Palmer S. The impact of cortical remapping interventions on pain and disability in chronic low back pain: a systematic review. Physiotherapy 2015; 101: $25-33$.

- Kälin S, Rausch-Osthoff AK, Bauer CM. What is the effect of sensory discrimination training on chronic low back pain? A systematic review. BMC Musculoskelet Disord 2016; 17: 143.

- Massé-Alarie H, Schneider C. Revisiting the corticomotor plasticity in low back pain: challenges and perspectives. Healthcare 2016a; 4: 67. 
- Pelletier R, Higgins J, Bourbonnais D. Addressing neuroplastic changes in distributed areas of the nervous system associated with chronic musculoskeletal disorders. Phys Ther 2015; 95(11): 1582-91.

- Massé-Alarie H, Flamand VH, Moffet H, Schneider C. Peripheral neurostimulation and specific motor training of deep abdominal muscles improve posturomotor control in chronic low back pain. Clin J Pain 2013; 29: 814-823.

- Schabrun SM, Hodges PW. People with low back pain display atypical responses to brain based treatments. World Congress on Low Back and Pelvic Girdle Pain 2016 Singapore.

- Mochcovitch MD, da Rocha Freire RC, Garcia RF, Nardi AE. A systematic review of fMRI studies in generalized anxiety disorders: evaluating its neural and cognitive basis. $J$ Affect Disord 2014; 167: 336-42.

- Kaiser RH, Andrews-Hanna JR, Wager TD, Pizzagalli DA. Large-scale network dysfunction in major depressive disorder: a meta-analysis of resting-state functional connectivity. JAMA Psychiatry 2015; 72(6): 603-11.

- Peters SK, Dunlop K, Downar J. Cortico-striatal-thalamic loop circuits of the salience network: a central pathway in psychiatric disease and treatment. Front Syst Neurosci 2016; 10: 104.

- Zhang K, Zhu Y, Zhu Y, et al. Molecular, functional, and structural imaging of major depressive disorder. Neurosci Bull 2016; 32(3): 273-85.

- Beckmann CF, DeLuca M, Devlin JT, Smith SM. Investigations into resting-state connectivity using independent component analysis. Philos Trans $R$ Soc Lond B Biol Sci 2005; 360: 1001-31. 
- Tomasi D, Volkow ND. Functional connectivity density mapping. Proc Natl Acad Sci USA 2010; 107: 9885-90.

- Pijnenburg M, Hosseini H, Brumagne S, Janssens L, Goossens N, Caeyenberghs K. Structural brain connectivity and the sit-to-stand-to-sit performance in individuals with nonspecific low back pain: a diffusion MRI based network analysis. Brain Connect 2016; 6(10): 795-803. 


\section{Figure legends}

Fig. 1 Preferred Reporting Items for Systematic reviews and Meta-Analyses flow chart of the study selection process 


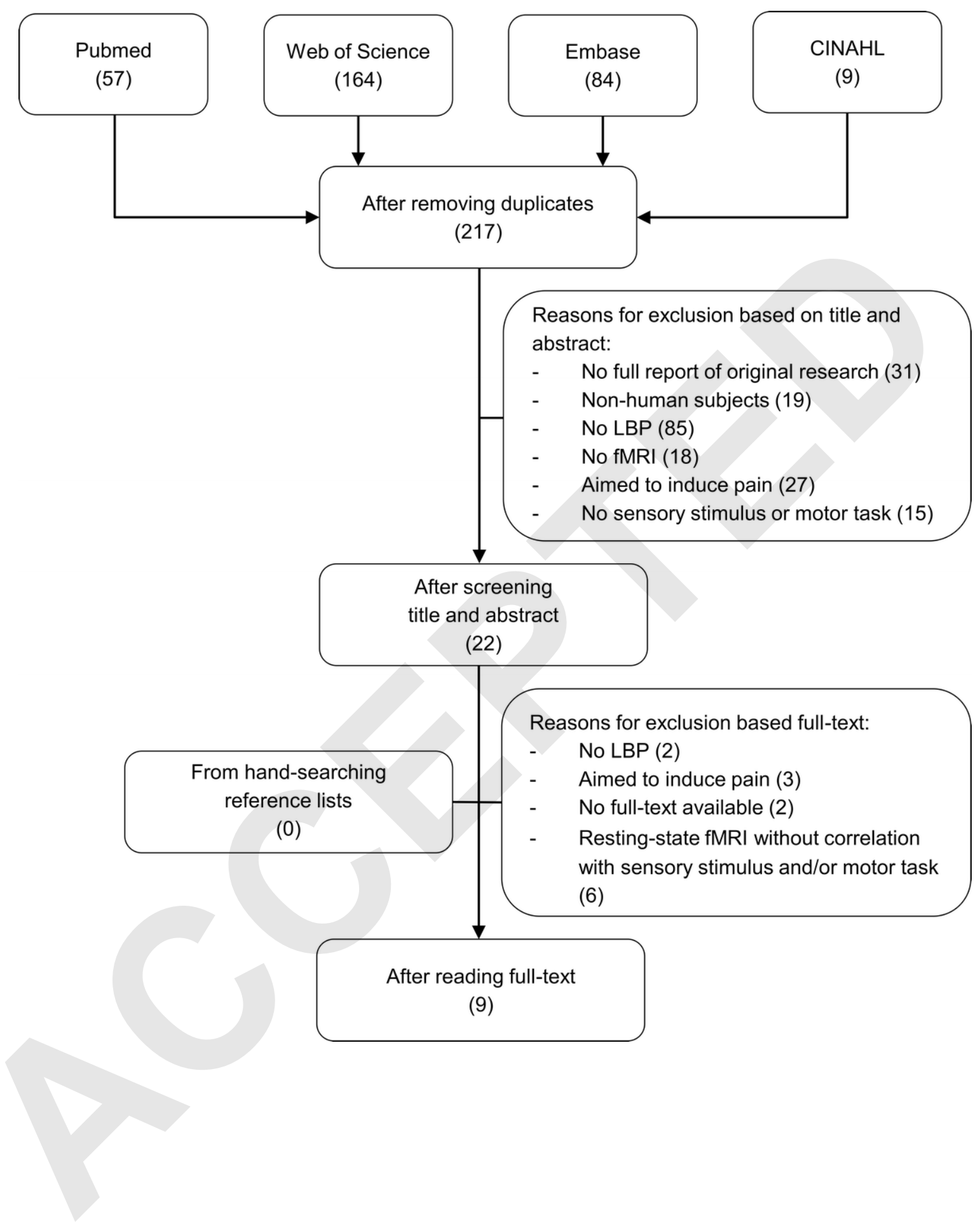


Table 1. Eligibility criteria

\section{Inclusion criteria}

\section{Exclusion criteria}

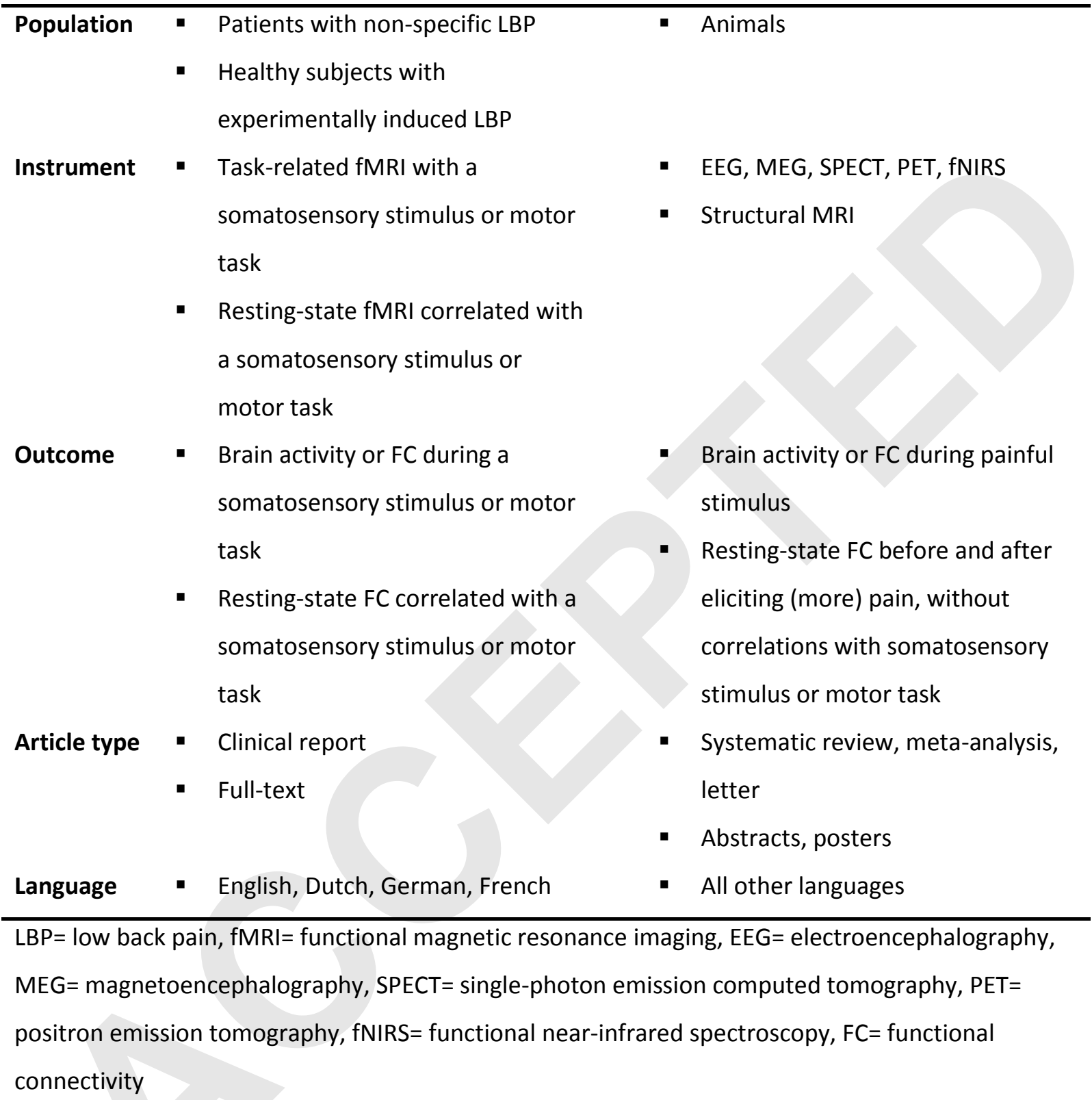


Table 2. Summary of evidence on $\mathrm{FMRI}$ changes during somatosensory processing or motor performance in subjects with LBP

\begin{tabular}{|c|c|c|c|c|c|c|}
\hline $\begin{array}{l}\text { Author, } \\
\text { year }\end{array}$ & LBP group & Control group & $\begin{array}{l}\text { fMRI, stimulus and } \\
\text { motor task }\end{array}$ & Main findings on group differences & Correlations & Remarks \\
\hline $\begin{array}{l}\text { Buckalew et } \\
\text { al. } 2010^{36}\end{array}$ & $\begin{array}{l}\text { - Disabling chronic } \\
\text { LBP, } 4 \mathrm{~F} / 4 \mathrm{M}, 74 \pm 6 \\
\text { y } \\
\text { - Non-disabling } \\
\text { chronic LBP, } \\
2 \mathrm{~F} / 6 \mathrm{M}, 75 \pm 7 \text { y }\end{array}$ & NA & $\begin{array}{l}\text { RS, physical } \\
\text { performance }\end{array}$ & $\begin{array}{l}\text { Disabling LBP: } \uparrow \text { FC of medial PFC } \\
\text { Non-disabling LBP: } \uparrow \text { FC of lateral } \\
\text { PFC } \\
\text { Physical performance: no difference }\end{array}$ & $\begin{array}{l}\text { No correlation } \\
\text { between } \mathrm{FC} \text { and } \\
\text { physical } \\
\text { performance }\end{array}$ & $\begin{array}{l}\text { PCC as seed } \\
\text { region in RS- } \\
\text { fMRI data } \\
\text { analysis }\end{array}$ \\
\hline $\begin{array}{l}\text { Gay et al. } \\
2014^{37}\end{array}$ & $\begin{array}{l}\text { Healthy with } \\
\text { induced LBP, } \\
17 F / 7 M, 22 \pm 4 \text { y }\end{array}$ & NA & $\begin{array}{l}\text { RS, before and } \\
\text { after spinal } \\
\text { manipulation, } \\
\text { mobilization and } \\
\text { touch }\end{array}$ & $\begin{array}{l}F C \text { changes common to three stimuli } \\
\text { between } L P C C-L \text { ant insula, } L \text { post } \\
\text { insula - LPAG, L } S 1 \text { - R post insula } \\
\text { Stimuli-dependent } F C \text { changes } \\
\text { between R S1 - R ant insula, R S1 - R } \\
\text { PAG, R ant insula - L PCC }\end{array}$ & $\begin{array}{l}\text { Small correlations } \\
\text { between } \mathrm{FC} \text { and } \\
\text { pain intensity and } \\
\text { between } \mathrm{FC} \text { and } \\
\text { pressure pain } \\
\text { sensitivity }\end{array}$ & $\begin{array}{l}\text { Only "pain- } \\
\text { related" } \\
\text { regions and } \\
\text { descending } \\
\text { pain } \\
\text { modulatory } \\
\text { region (PAG) } \\
\text { analyzed }\end{array}$ \\
\hline $\begin{array}{l}\text { Giesecke et } \\
\text { al. } 2004^{38}\end{array}$ & $\begin{array}{l}\text { Chronic non- } \\
\text { specific LBP, } 8 F / 3 M \text {, } \\
44 \pm 13 \text { y }\end{array}$ & $\begin{array}{l}\text { Healthy } \\
4 \mathrm{~F} / 7 \mathrm{M}, 41 \pm 7 \mathrm{y}\end{array}$ & $\begin{array}{l}\text { Task-related, } 2 \mathrm{~kg} \\
\text { pressure on } L \\
\text { thumb }\end{array}$ & $\begin{array}{l}\angle B P: \uparrow \text { activation in } \mathrm{R} S 1, \mathrm{~L} \& \mathrm{R} S 2, \mathrm{~L} \\
\text { cerebellum and } \mathrm{L} \text { inferior parietal } \\
\text { lobe } \\
\text { Healthy: } \uparrow \text { activation in R S2 }\end{array}$ & NA & $\begin{array}{l}\text { Only "pain- } \\
\text { relevant" } \\
\text { regions } \\
\text { analyzed }\end{array}$ \\
\hline $\begin{array}{l}\text { Hotz- } \\
\text { Boender- } \\
\text { maker } \\
\text { et al. } 2016^{39}\end{array}$ & $\begin{array}{l}\text { Chronic non- } \\
\text { specific LBP, } 5 F / 8 M \text {, } \\
39 \pm 15 \text { y }\end{array}$ & $\begin{array}{l}\text { Healthy } \\
5 \mathrm{~F} / 9 \mathrm{M}, 42 \pm 18 \mathrm{y}\end{array}$ & $\begin{array}{l}\text { Task-related, } \\
\text { manual pressure } \\
\text { on } 3 \text { lumbar } \\
\text { vertebrae }\end{array}$ & $\begin{array}{l}\angle B P: \downarrow \text { activation in L\&R S2, blurred } \\
\text { representation of vertebrae in S2 } \\
\text { Healthy: distinct representations of } \\
\text { vertebrae in } S 2\end{array}$ & NA & $\begin{array}{l}\text { Only S1 and S2 } \\
\text { analyzed }\end{array}$ \\
\hline $\begin{array}{l}\text { Lloyd et al. } \\
2008^{40}\end{array}$ & $\begin{array}{l}\text { Chronic non- } \\
\text { specific LBP with } \\
\text { - low degree of } \\
\text { pain-related } \\
\text { illness behavior, } \\
\mathrm{n}=15,46 \pm 13 \text { y } \\
\text { - high degree of }\end{array}$ & $\begin{array}{l}\text { Healthy } \\
9 \mathrm{~F} / 8 \mathrm{M}, 31 \pm 8 \text { y }\end{array}$ & $\begin{array}{l}\text { Task-related, tactile } \\
\text { vibration at lumbar } \\
\text { spine }\end{array}$ & $\begin{array}{l}\text { LBP with low illness behavior } \\
\text { - vs. healthy: } \uparrow \text { activation in L } \\
\text { superior parietal lobe, extrastriate } \\
\text { cortex, fusiform gyrus } \\
\text { - vs. LBP with high illness behavior: } \\
\text { 个 activation in R PCC, R extra- } \\
\text { striate cortex, L post parietal lobes }\end{array}$ & $\begin{array}{l}\text { LBP with low } \\
\text { illness behavior: } \\
\text { negative } \\
\text { correlation } \\
\text { between } \\
\text { activation in } R \\
\text { PCC, L post }\end{array}$ & NA \\
\hline
\end{tabular}


pain-related

illness behavior,

$n=13,44 \pm 12 y$ $\begin{array}{ll}\text { Moseley } & \text { Disabling chronic } \\ 2004 a^{41} & \text { LBP }, 1 F, 36 \text { y }\end{array}$

Pijnenburg

et al. $2015^{42}$

Chronic non-

specific LBP,

$11 \mathrm{~F} / 6 \mathrm{M}, 33 \pm 8 \mathrm{y}$

$\begin{array}{ll}\text { Shi et al. } & \text { Healthy with } \\ 2015^{43} & \text { induced LBP, } \\ & \text { 11F/17M, age } \\ & \text { range } 22-30 \text { y }\end{array}$

Vrana et al.

$2015^{44}$

specific LBP,
LBP with high illness behavior

- vs. healthy and LBP with low illness behavior: S1 activation medially shifted

Before pain education: activation in

Task-related, abdominal muscle contraction

\section{Healthy}

$12 \mathrm{~F} / 5 \mathrm{M}, 32 \pm 8 \mathrm{y}$

$\mathrm{RS}$, duration to

perform 5 sit-to-

stand-to-sit

movements when

blindfolded

NA

Task-related, real

and sham

acupuncture at

knee

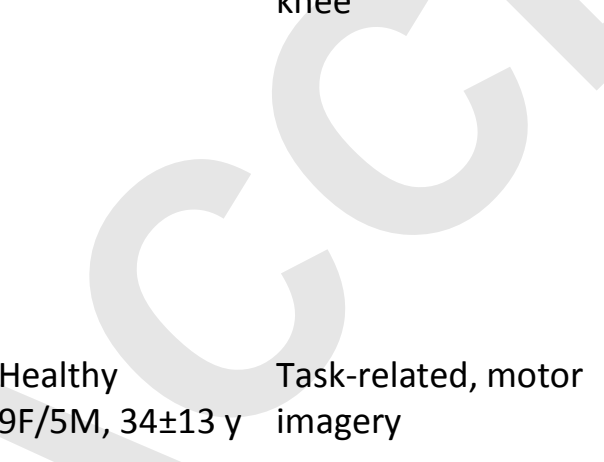

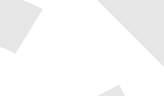

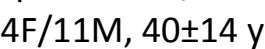

$9 F / 5 M, 34 \pm 13$ y imagery
S1, ACC, insula, parietal association and frontal cortices

After pain education: $\downarrow$ activation in all regions, except for $S 1$

$\angle B P: \downarrow F C$ in L SMA, M1, S1 and

cerebellar lobules IV-V + 个 FC in R

middle frontal gyrus, superior

frontal gyrus, lobule VI of vermis +

worse sensorimotor performance

Acupuncture vs. baseline:

deactivation in somatosensory and

limbic system, pain matrix, DMN,

thalamus + activation in $\mathrm{M} 1, \mathrm{~S} 1$,

SMA, insula, midcingulate cortex

Sham versus. baseline: deactivation in insula, frontal operculum, M1 +

activation in somatosensory, limbic and attentional systems, DMN,

thalamus, cerebellum, lateral

occipital gyrus

LBP: $\downarrow$ activity in L SMA and R STG,

NA

$\begin{array}{ll}\text { Total group: } & \text { Only } \\ \text { negative } & \text { sensorimotor } \\ \text { correlation } & \text { network } \\ \text { between FC of } & \text { analyzed }\end{array}$

cerebellar lobules

IV-V, M1 and task

performance

NA

$\uparrow$ task-related FC in majority of

motor imagery-network

Healthy controls: $\uparrow$ task-related FC

in thalamus

Motor imagery performance: no
NA

parietal lobes and

catastrophizing

NA

NA

nalyzed

Only motor

imagery-

related regions,

STG and

primary

auditory cortex 
<smiles>[Te]C1C=C1</smiles> 
Table 3. Risk of bias in included articles (cfr. modified Downs and Black tool ${ }^{45,47,48}$ )

\begin{tabular}{|c|c|c|c|c|c|c|c|c|c|}
\hline & $\begin{array}{l}\text { Vrana } \\
\text { et al. } \\
2015^{44}\end{array}$ & $\begin{array}{l}\text { Giesecke et } \\
\text { al. } 2004^{38}\end{array}$ & $\begin{array}{c}\text { Hotz-Boender- } \\
\text { maker et al. } 2016^{39}\end{array}$ & $\begin{array}{l}\text { Lloyd et } \\
\text { al. } \\
2008^{40}\end{array}$ & $\begin{array}{l}\text { Moseley } \\
2004 a^{41}\end{array}$ & $\begin{array}{l}\text { Shi et } \\
\text { al. } \\
2015^{43}\end{array}$ & $\begin{array}{l}\text { Pijnen-burg } \\
\text { et al. } 2015^{42}\end{array}$ & $\begin{array}{l}\text { Buckalew et } \\
\text { al. } 2010^{36}\end{array}$ & $\begin{array}{l}\text { Gay et } \\
\text { al. } \\
2014^{37}\end{array}$ \\
\hline \multicolumn{10}{|l|}{ Reporting } \\
\hline Aims described & 1 & 0 & 1 & 1 & 1 & 0 & 1 & 1 & 1 \\
\hline Outcomes described & 1 & 1 & 1 & 1 & 1 & 1 & 1 & 1 & 1 \\
\hline Patients' characteristics & 1 & 1 & 0 & 0 & 1 & 0 & 1 & 1 & 1 \\
\hline $\begin{array}{l}\text { Distribution of } \\
\text { confounders }\end{array}$ & 1 & 1 & 1 & 1 & NA & NA & 1 & 1 & 1 \\
\hline Main findings & 1 & 1 & 1 & 1 & 0 & 1 & 1 & 0 & 1 \\
\hline $\begin{array}{l}\text { Random variability of } \\
\text { findings }\end{array}$ & 1 & 1 & 1 & 1 & 0 & 1 & 1 & 1 & 1 \\
\hline Actual $p$-values reported & 0 & 0 & 1 & 1 & 0 & 1 & 1 & 1 & 0 \\
\hline \multicolumn{10}{|l|}{ Validity } \\
\hline $\begin{array}{l}\text { Those asked to } \\
\text { participate } \\
\text { representative } \\
\text { Those willing to }\end{array}$ & 1 & 1 & 0 & 0 & 0 & 0 & 0 & 0 & 1 \\
\hline $\begin{array}{l}\text { participate } \\
\text { representative }\end{array}$ & 0 & 0 & 0 & 0 & 0 & 0 & 0 & 0 & 1 \\
\hline \multicolumn{10}{|l|}{ Bias } \\
\hline Data dredging & 0 & 0 & 0 & 0 & 0 & 0 & 0 & 0 & 0 \\
\hline $\begin{array}{l}\text { Appropriate statistical } \\
\text { analysis }\end{array}$ & 1 & 1 & 1 & 1 & 1 & 1 & 1 & 1 & 1 \\
\hline $\begin{array}{l}\text { Accurate outcome } \\
\text { measures }\end{array}$ & 1 & 1 & 1 & 1 & 1 & 1 & 1 & 1 & 1 \\
\hline \multicolumn{10}{|l|}{ Confounding } \\
\hline $\begin{array}{l}\text { Groups recruited from } \\
\text { similar population }\end{array}$ & 1 & 0 & 0 & 0 & NA & NA & 0 & 1 & NA \\
\hline
\end{tabular}




\begin{tabular}{|c|c|c|c|c|c|c|c|c|c|}
\hline $\begin{array}{l}\text { Groups recruited over } \\
\text { same time }\end{array}$ & 0 & 0 & 0 & 0 & NA & NA & 0 & 0 & NA \\
\hline Adjusted for confounding & 1 & 1 & 1 & 0 & NA & NA & 1 & 1 & 1 \\
\hline Total (\%) & $73 \%$ & $60 \%$ & $60 \%$ & $53 \%$ & $45 \%$ & $55 \%$ & $67 \%$ & $67 \%$ & $85 \%$ \\
\hline
\end{tabular}

